\title{
Las explicaciones del marxismo
}

\section{Elisabetta Di Castro}

Paulette Dieterlen, Marxismo analítico: explicaciones funcionales e intenciones. México, UNAM, Coord. Gral. de Estudios de Posgrado/FFYL, 1995, 256 pp. (Seminarios)

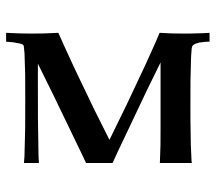

ás allá de los diversos marxismos y de sus correspondientes pretensiones de fidelidad a las fuentes originales, una gran gama de los principales acontecimientos del siglo $\mathrm{xx}$ pueden enmarcarse dentro de la polémica pro o contra las ideas marxistas. Hace apenas unos años, con la caída del muro de Berlín, se anunciaba la definitiva retirada del socialismo de la escena de la historia, pero, incluso desde la euforia de los supuestos vencedores, el destino de las reformas políticas y económicas se presenta todavía hoy bastante incierto. En este sentido, parecería que un fantasma sigue recorriendo a la vieja Europa, y no sólo a ella.

Sin embargo, también se debe señalar que, a pesar de todos los matices y observaciones posibles, como propuesta teórica y política, el marxismo no puede ser inmune al gran fracaso del experimento iniciado en 1917. Entre las lecciones pagadas con altísimos costos destaca el frecuente descuido de una serie de temas que se consideraban tradicionalmente vinculados al liberalismo y al capitalismo, siendo sin duda uno de los principales el problema del individuo. Y, paradójicamente, el ideal de un sistema más justo y humano lo tiene como centro: es el individuo quien da sentido a la lucha contra el capital, y, podemos agregar, contra la dictadura de la burocracia. De esta manera, si alguna pertinencia puede tener todavía hoy el marxismo ésta será a partir de su acercamiento a otros marcos conceptuales que le permitan replantear viejos y nuevos problemas.

$\mathrm{Al}$ menos por lo que se refiere al ámbito teórico, desde 1978 con el libro de G. A. Cohen titulado Karl Marx's theory of history: a defence, se inaugura una fértil conjunción cuando la filosofía analítica extiende su campo de estudio a los problemas del marxismo. Así, a partir de una escuela que "no veía nada de filosófico" en esta corriente, Cohen logró llamar la atención sobre la relevancia de algunos de sus temas principales, al grado de que se fue consolidando una nueva escuela conocida hoy como marxismo analítico. En especial, los marxis- 
tas analíticos se han preocupado por tres campos problemáticos: uno de carácter ético que gira en torno a la injusticia del capitalismo y la necesidad de una sociedad igualitaria; otro de carácter económico que cuestiona la teoría del valor y de la explotación capitalista; y uno más de carácter metodológico que reflexiona sobre la clase de explicaciones formuladas por Marx. Este último es el campo problemático que desarrolla Paulette Dieterlen en su libro Marxismo analitico: explicaciones funcionales e intenciones.

Ubicados en los problemas metodológicos, la principal polémica dentro del marxismo analítico la sostuvieron el propio Cohen y Jon Elster. Por un lado, el primero reconstruye al materialismo histórico como una teoría que ofrece explicaciones de tipo funcional; por otro, el segundo insiste en que para dar cuenta de la estrategia de la lucha de clases, piedra angular de dicho materialismo, es necesario recurrir a explicaciones de tipo intencional. Obviamente, la relevancia de esta polémica no descansa sólo en la puesta en juego de una clase de explicación sino también en la posible atribución de los cambios sociales a ciertas estructuras o a los individuos, y, finalmente, en la defensa de cierto determinismo o de la intencionalidad de los agentes en el desarrollo histórico. Planteamientos frente a los cuales Dieterlen se preocupa por defender la posible compatibilidad entre los dos tipos de explicaciones contrapuestas.

Para abordar la polémica Cohen-Elster, la autora analiza minuciosamente las discusiones en torno a las explicaciones funcionales e intencionales no sólo dentro del marxismo, y, en especial, retoma del sociólogo Robert Merton la idea de que sí es posible incorporar las intenciones de los agentes en las explicaciones funcionales (las llamadas funciones manifiestas). De hecho, después de analizar la propuesta de Cohen, Dieterlen destaca cómo finalmente en su reconstrucción del materialismo histórico se incorporan las intenciones de los agentes: al conciliar la supuesta inevitabilidad del cambio social con la motivación que tienen los agentes para incorporarse al movimiento revolucionario; al sostener que el desarrollo de las fuerzas productivas presupone que los hombres son racionales; $y$, por último, en tanto es necesario el reconocimiento de la pertinencia de ciertas relaciones de producción para el propio desarrollo de las fuerzas productivas.

En relación a Elster, la autora nos propone recuperar sus críticas a las pretensiones de que un dispositivo que es legítimo sólo en la biología se extienda a las ciencias sociales y así poder sostener que en éstas el mecanismo adecuado es el intencional. En otras palabras, por lo que se refiere en especial a las ciencias sociales, las únicas explicaciones correctas serían las que parten de las creencias, deseos e intenciones de los agentes.

Sin embargo, frente a las dificultades en las que cae Cohen para defender las 
explicaciones funcionales, Philippe van Parijs propone reconstruir al materialismo histórico como un mecanismo causal de refuerzo. Se trataría, entonces, de una teoría que puede explicar por qué, en determinados momentos históricos, se equilibran y desequilibran las relaciones de producción con respecto a las fuerzas productivas. Para lograrlo recurre a un mecanismo de optimización local, el cual también es cuestionado por Dieterlen en la medida en que la explicación del cambio de unas relaciones de producción a otras va a exigir más bien el recurso a un mecanismo de optimización global. Pero, por lo que se refiere en especial al tipo de explicaciones, la autora destaca que en las ciencias sociales las explicaciones funcionales e intencionales lejos de ser incompatibles se refuerzan y enriquecen. En el propio pensamiento de Marx, por ejemplo, el cambio de creencias es fundamental, al grado de que puede motivar, sin recurrir al estado de crisis, a que los agentes busquen establecer otras relaciones de producción.

Como concluye Dieterlen,

[...] es posible reconstruir el materialismo histórico como una teoría que ofrece explicaciones funcionales, y que dichas explicaciones son legítimas si hacemos explícito el mecanismo causal de las acciones de los individuos. Lo anterior significa que debemos explicar cómo los miembros de una clase social determinada, con ciertas creencias, que surgen de unas relaciones de producción, pueden descubrir la relación de éstas con las creencias y así tengan la posibilidad de cambiarlas. (p. 234)

Conclusión que inmediatamente después es matizada al señalarse que con ello no se está comprometiendo a que toda explicación en ciencias sociales deba recurrir a algún mecanismo funcional. De hecho, Dieterlen sostiene que ciertos problemas en el ámbito de la política y la economía pueden, y parecería que deben, como sostiene el individualismo metodológico, ser explicados a partir de las intenciones de los agentes. Con lo que finalmente se confirma la impresión que nos ha acompañado a lo largo de la obra, de que en última instancia la explicación en las ciencias sociales, aunque llegue a incorporar algunos elementos funcionales, sigue siendo intencional.

Sin embargo, la relevancia del texto de Dieterlen no descansa tanto en sus conclusiones sino en el dejar sobre la mesa de discusión algunos aspectos teóricos que, ciertamente, más allá de que la práctica política del marxismo ya no sea vigente, no pueden simplemente ser abandonados. Problemas teóricos a los que hay que sumar también la vigencia del reto al que el marxismo pretendía hacer frente: la organización de una sociedad más justa. En este sentido, precisamente en estos días en que, en distintos espacios y desde diversas perspecti- 
vas, se arremete contra Marx tratándolo como a un "perro muerto", nos congratulamos de la aparición de un texto como el de Dieterlen con el que se puede declarar la pertinencia de aquel pensador y hasta llegar a coquetear de vez en cuando con su peculiar lenguaje. Ciertamente, también nosotros podríamos sostener que el hecho de que el marxismo haya sufrido en este siglo una "mistificación", no obsta para que esta propuesta haya expuesto algunos de los principales problemas de la sociedad contemporánea. Aunque ya no es cuestión simplemente de poner de pie lo que se presupone se encuentra de cabeza, podemos descubrir bajo su corteza mística también una semilla racional.

Como bien se señaló en su momento, no se trata tanto de ser marxista, sino de ver en la propuesta de Marx, como en cualquier clásico, un punto de partida tal vez necesario pero no suficiente para reflexionar sobre nuestra realidad. El texto de Dieterlen es uno de esos intentos que además viene a cubrir un segundo hueco: ni siquiera en los momentos de auge del marxismo se discutió ampliamente en México su vertiente analítica, lo que sin duda puede al menos ahora enriquecer las discusiones sobre esos problemas e ideales que siguen urgentemente vigentes. 